31_ Wirkung des Gebets bei internistischen und kardiologischen Erkrankungen

35_ Spiritualität und Krebserkrankung

39_ Caring - Christliche Werte in der Medizin

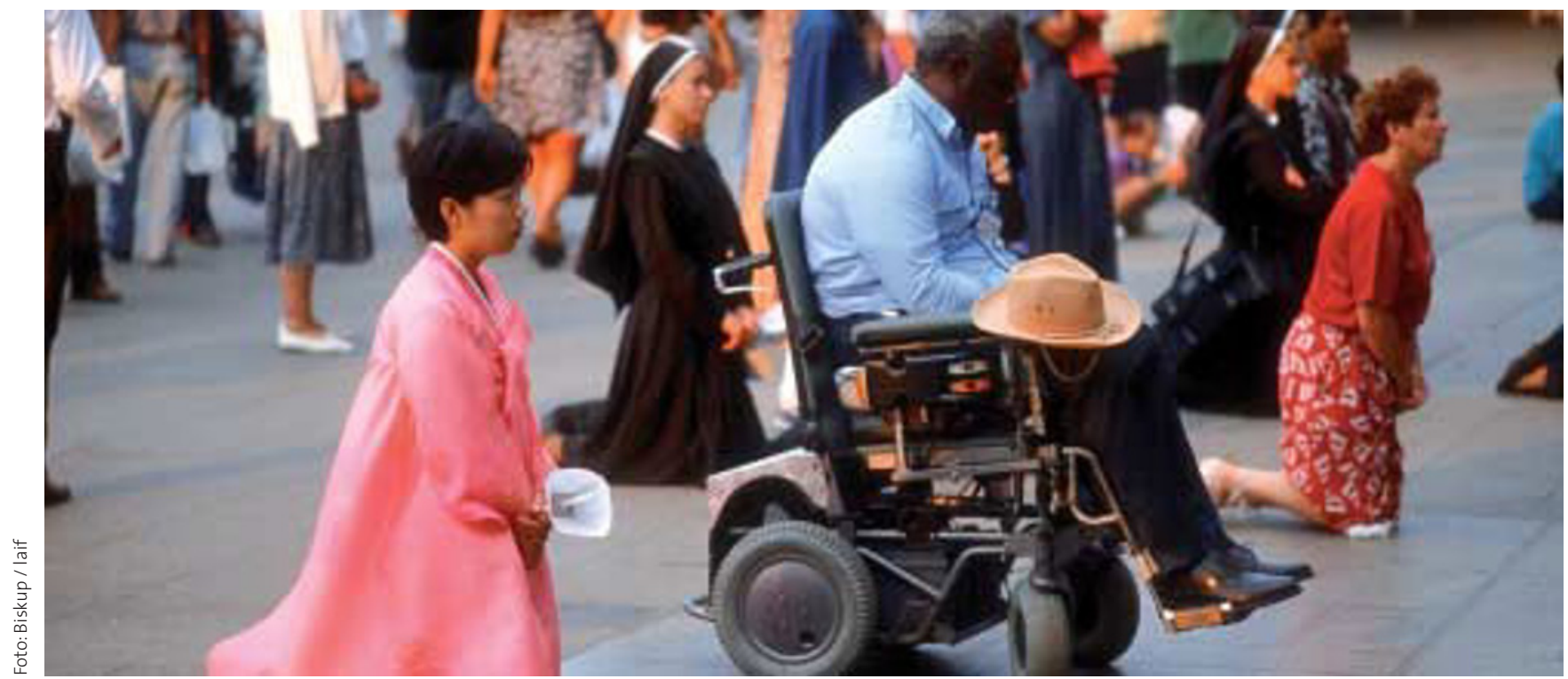

Christliche Werte in der Medizin

\title{
Profitieren Kranke von einer religiösen Einstellung?
}

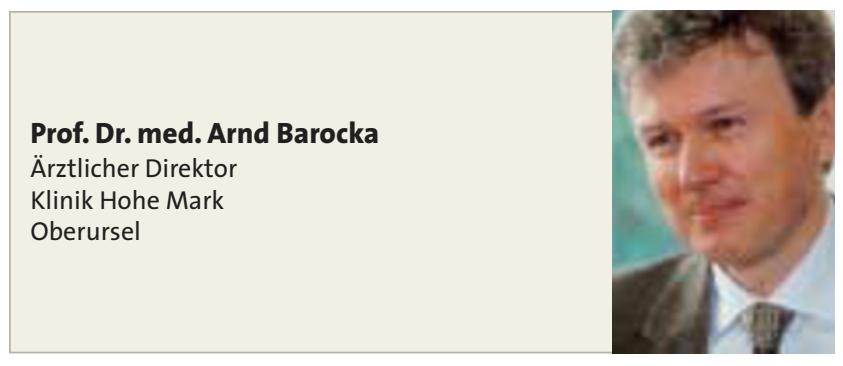

— Der Einfluss religiöser Einstellungen auf Gesundheitsverhalten und Krankheitsverläufe ist jedem Arzt bekannt, aber nicht immer leicht zu fassen. Glaubensheilungen - an sich außermedizinische Konstrukte - werden immer wieder auch von Medizinern dargestellt [1]. Vermehrt gibt es in den letzten zehn Jahren systematische epidemiologische Untersuchungen zum Einfluss einer religiösen „Exposition“ auf das Gesundheitsverhalten [2]. Auch die Psychotherapie öffnet sich vorsichtig für religiöse Symbole und Interventionen [3]. Diese Entwicklung wirft eine Reihe von Fragen auf: Wie ist die methodische Qualität der Daten? Kann man die Befunde von den
Vereinigten Staaten auf Europa übertragen? Welche persönlichen Werte und Einstellungen liegen den erhobenen Daten zugrunde? Kann man spirituelle Phänomene überhaupt statistisch erfassen? Um diesen Fragen näherzukommen, analysieren die Autoren Hefti und Koenig zunächst einige besonders spektakuläre Studien über den Einfluss des Gebets auf den Therapieverlauf. Hier geht es vor allem um das Geschehen auf kardiologischen Intensivstationen, aber auch um Krankheitsverläufe bei rheumatoider Arthritis. In einem Beitrag aus dem Bereich der Onkologie präsentieren Csef und Hefner Argumente dafür, mehr Spiritualität in die Medizin zu integrieren. Der Beitrag von Scharrer schließlich ist nicht empirisch, sondern eine sehr persönlich gehaltene Darstellung von Werten, die man akzeptieren oder ablehnen kann. Doch dies sind genau die Einstellungen und Werte, die den zuvor dargestellten epidemiologischen Effekten zugrunde liegen. Nicht zuletzt berühren sie das ärztliche Selbstverständnis, das zurzeit ohnehin erheblichen Belastungen ausgesetzt ist.

(Literatur beim Verfasser: barocka@hohemark.de) 